\title{
Consideraciones sobre problemáticas del adolescente a través de la patología
}

DRES.: MARIO PEREZ *, MARIO SEPULVEDA *, CARLOS ALMONTE *.

La pubertad es un fenómeno biosicológico producto del desequilibrio hormonal originado por la actividad de las glándulas sexuales responsables de Jas transformaciones somatosíquicas que hace del niño un hombre biológicamente maduro, apto para la reproducción. En suma, la pubertad es el puente, la transición, entre el niño y el adulto. Los extremos de este puente biológico se pueden medir y por lo tanto determinar dentro de límites más o menos precisos para las variaciones humanas. Variaciones que dependen de los mismos factores a que está sometido el hombre; la raza, el clima, la alimentación, el avance de la civilización, etc., provocan fluctuaciones entre una región y otra, pero de escasa importancia en números absolutos.

El niño tiene características biológicas, psicológicas y sociológicas que to hacen diferente del adulto. Su cuerpo, aún no desarrollado, no presenta en el niño distinciones claras entre ambos sexos. En el ámbito psíquico es el pensamiento lo que marca el distingo mayor entre ellos, con un mundo infantil en que prevalece la fantasía y que las cosas son en la realidad como se perciben en la irrealidad del mundo interior, contra otro mundo en que la reflexión, el juicio y la lógica se objetivan en la realidad de lo percibido. Socialmente ambos tienen un papel, un lugar y funciones a cumplir claramente establecida a través de pautas de conducta que permiten la realización limitada o ilimitada, dependiente o independiente de las probabilidades hercdadas $\mathrm{y}$ de las posibilidades existenciales.

El niño en cualquicra raza o cultura tiene características semejantes cambiando sólo su significación cultural, pero no en cl sentido en sí que encierra su vida como potencial reviviente generacional conservador de la especie.

\footnotetext{
* Setvicio de Psiquìtría, Hospital Roberto del Río. Departamento de Psiquiatróa y Salud Mental, Ud, de Chile, Scde Nort:-
}

La pubertad marca el distingo y es el período de transición entre el niño y el adulto. Es el período en que bajo la llama de la madurez sexual se quema la ingenua fantasía de lo probable para ser lo posible entre lo heredado, lo madurado y lo recibido del ambiente. La pubertad inicia al individuo en los secretos de la generación, lo pone frente a los sexos y a su ubicación en la sociedad, en el mundo y frente a él mismo; le abre la perspectiva de trascender. Este paso, sencillo en las ci. vilizaciones primitivas se ha hecho cada vez más prolongado y difícil en las culturas avanzadas yendo más allá de lo biológico y más allá de lo fisiológico para depender de lo social y terminar en limites imprecisos, sin tener deberes que ejercer ni cumplir a través de pautas bien regladas.

Este periodo en que el niño pasa a ser hombre joven, en que fisiológicamente se centra en la sexualidad, psicológicamente en el equilibrio y la madurez que proporcionan el saber lo que se debe hacer y dónde pertenecer, socialmente no tiene papel ni lugar bien determinados y que bien podría prolongarse por exigencias de la cultura o termina por imposición accidental o económica. Este proceso de madurez biofisiológica, de búsqueda del equilibrio psicológico y de jnmadurez social, se ha llamado adolescencia.

La adolescencia es entonces un fenómeno de maduración socio-cultural, pues antropológicamente existe sólo la juventud como ingénita al desarrollo biofisiológico humano. La juventud es propia a la evolución madurativa de un ser que transita desde el nacimiento a la muerte.

Este hombre joven quẽ en la pubertad ha dejado de ser niño, que está dotado de todas las funciones mentales y biológicas que desarrollará hacia el equilibrio y la madurez, se llena del contenido que le entrega la sociedad y la cultura en un plazo mayor o menor según el nivel tecnológico y cien- 
tífico de clla. Es un período que su comienzo to senala la pubertad, pero que su determinación si difunde más o menos rápido con la madurez. Es un tiempo de aprender; la preparación para ser adulto. Adolescencia es pues, un fenómeno cultural entroncado en los marcos socio-cconómicos y en la política de la nación a la cual el joven pertenece.

Es así cómo cste joven constituirá una unidad polar individuo-medio social pero con una profunda conflictiva. Conflictiva que se da tanto interna como externamente. En lo interno por su contradicción entre madurez sexual y conciencia rezagada, entre vitalidad e inseguridad, entre exbuberancia de fuerza corporal y falta de capacidad de expresión (Fisher). Contradicción externa con la socicdad interesada en introducirlo en la cultura, incorporarlo al mundo de los valores, pero que él por su sentido de lo absoluto y de los abstractos, sólo los aceptará en la pureza de su significación, criticando las transacciones de los adultos y precipitando con ello la conflictiva o la crisis.

Las características de esta edad como: descubriniento y sobreestimación del yo, egocentrismo y subjetivismo, actitud reflexiva y crítica con respecto a la vida psíquica de los demás, actitud idealista, intransigencia, impulso de independen. cia y hacerse valer, exaltación de los sentimientos, impresionabilidad apasionada, variaciones de ánimo, impulso al aislamiento, etc, tienen el sello de la inestabilidad y de lo transicional, originando las condiciones para comportamientos críticos y peculiares con límites incicrtos entre lo normal y la patológico.

La juventud con estas características es un transcurso histórico biográfico del hombre en lo individual y que en lo colectivo sufre los embates de la historia de la humanidad. Por cllo se vivirá y se mostrará este período de modo diferente en las diversas etapas evolutivas de la cultura. El problema juveril emergerá en las etapas críticas de dicha cultura con relieves tanto más marcado cuanto mayor sea la crisis cultural.

La evolución del niño al adulto maduro dependerá de lo cultural, tanto en su inserción sociobiológica como en la sociocultural misma, por las contradicciones ya expuestas a que se somete al јоven en maduración. En los dos puntos de inserción, cuando las restricciones externas o internas hacen crisis, aparece la crisis puberal o la crisis juvenil.

Siguiendo a Kretchner, consideramos que "las crisis puberales no son enfermedades ni neurosis, tampoco factores constitucionales cstables, sino que más bien son cursos fásicos constitucionalmente circunscritos, que están vinculados a la pubertad y que con dimensiones aumentadas ilustran todas las dificultades biológicas normales de este punto de tránsito psicofísico".
En cambio entendemos por crisis juvenil uni etapa existencial crílica y angustiante provocada por la problematización del joven de su condición como individuo, su proyección y significación y su actitud frente a los valores.

Vemos así cómo las finalidades del desarrollo se hallan determinadas en importante medida por las propias capacidades de crecimiento del joven, pero se ha demostrado también que están influidas por las demandas que le impone el medio cultural cn que vive. En otras palabras, los cambios básicos que se producen nacen de la propia naturaleza del joven y están determinados en gran medida por la herencia, no obstante mucho de lo que sc considera típicamente adolescente, o que se es. pcra de los adolescentes, es un reflejo del medio cultural en que vive.

Con esta orientación pero sin exaltar, ninguno de los factores en juego y con el deseo de estudiar a través de nuestra experiencia el real valor de cada uno de ellos, en una actitud abjerta, nos dispusimos a la atención de un Consultorio Externo de Adolescencia en el Area Norte de Santiago. Por razones operativas y por no encontrar opiniones comunes fijamos como límites de edad, cl período que va de los 12 a los 18 años

Este es el primer estudio del trabajo de dos años (1970-1971). Se revisaron 266 fichas clínicas y nuestra intención ahora es mostrar algunos hallazgos sobre factores causales de las patologías cncontradas, su modo de expresarse, la dependencia a factores externos y su relación con problemáticas inherentes a esta etapa etaria.

Si consideramos que los trastornos de desarrollo de carácter, los desarrollos neuróticos, los trastornos de la personalidad, los cuadros psicofisiológicos y las deficiencias mentales corresponden al $66,5 \%$ de nuestra casuística, debemos aceptar que son los factores heredo-constitucionales los que aportan los fundamentos de la patología encontrada en este periodo y que la exigencia sociocultural produce la eclosión de cuadros larvados o que se venían organizando en etapas anteriores; ejemplo de esto lo constituye el hecho que del total de consultas a $54(24 \%)$ se le hizo por primera vez el diagnóstico de Debilidad Mental, como patología principal. El diagnóstico era desconocido por sus familiares y fueron las exigencias escolares las que pusieron de manifiesto la insuficiencia que dificultaba el rendimiento, motivando la consulta generalmente recomendada en el colegio.

En cambio, las reacciones y las crisis, por su corta evolución, muchas veces adquieren caracteristicas inherentes al periodo madurativo y con la impronta socio-cultural contemporánea. Es así como muchos púberes caen en reacciones no sólo por los trastornos provocados por la perturbación psicofísica, sino también por las exigencias del 
grupo de padrcs e incluso por la de los mismos padres, quiceses le cxigen actitudes o comportaciones para los que no están preparados, o por el contrario retardan su incorporación al grupo por excesiva aprensión, vigilancia y control, creando las condiciones para una dependencia c ineptitud para enfrentar la vida, o entregancio la semilla de una rebelión insolente o solapada. Encontramos así, por un lado el púber que desea seguir siendo niño por un tiempo más y por otro aquel que no desea seguir siendo considerado niño.

Estos adolescentes seres socialmente dependiente caen en patología también en gran medida dependiente de la conflictiva conyugal o familiar. En el $50 \%$ de nuestros consultantes sus cuadros tenían estrecha relación con graves conflictivas conyugales, siendo la embriaguez del padre o la psicopatía de alguno de ellos la causa más frecuente.

A pesar de sus pretensiones de independencia, dependen de su familia en la solución de sus problemas, $y$ son traidos o se hacen acompañar por sus parientes en $65 \%$. La consulta espontánea es bastante baja, sólo un 7,4\% (17) concurre por su propia iniciativa. Estos generalmente llegan solos. Que un 30\% no regrese después de la primera consulta y que otro porcentaje más o menos igual venga 2 ó 3 veces, podría bacer pensar que corresponde a los conducidos al Consultorio contra su voluntad, sin embargo, entre éstos hay algunos que concurricron solos o que siendo llevados quedaron comprometidos gratamente para regresar, pero no lo hicieron. Habría que apuntar a su inestabilidad como razón de este fenómeno.

Esta dependencia se expresa también en las conflictivas personales, pues un gran número de las perturbaciones psíquicas ticnen origen en el contex to psico-familiar y son secundarias a graves conflictos familiares o conyugales originadas por la presencia de un padre alcohólico, irresponsable o explosivo, o por las confrontaciones de diferentes acepciones valóricas generacionales, o por el nivel de aspiraciones personales o familiares. Estas situaciones provocan angustias y frustraciones, que perturban la maduración psíquica anormales, expresadas generalmente por conductas agresivas y alteraciones del medio y en menor frecuencia por aislamiento y rechazo. Por su situación de estar inmerso en una conflictiva social faniliar o generacional, el joven se perturba y se problematiza concretamente, originándose conflictos objetivos en el plano somático y conductual. La queja somática como manifestación del conflicto es muy frecuente; a veces como única expresión y otras, como lo que constituye el plano superficial y externo que aproxima a la problemática de fondo, que generalmentc también es concreta y se soluciona en gran medida con modificación ambiental. En esta muestra no se da la problemátici noćtica del joven de Spranger y sólo hemos encon- trado tres de las llamadas crisis juveniles. La crisis juvenil es raria en nuestro medio; aquí el joven tiene problcnáticas concretas. Se pentsó que ésta era una característica del joven latinoamericano, pero investigadores sociales europeos la cxtienden a sus jóvenes, al decir que el anhelo de los jóvenes modernos consta principalmente de deseos concretos y cosificados mezclados con el vago sentimiento de que falta algo decisivo, de que la vida, en el fondo, carece de contenido (Fisher). La problemática juvenil está enriarcada por su dependencia a la falta de rol y status social y variará en relación a situaciones ajenas a ella con las que adhiere o rechaza. Aceptación o rechazo que se mavifiestat con características propias dadas por su subjetividad, radicalismo, im . pulsividad e inestabilidad, dependiente de la contradicción entre vitalidad Íísica y limitación social, entre iniciativa y posibilidad de realización, entre anhelo y realidad (cntre abstracción y objetividad) entre madurez biológica temprana (puberal) y postergación del ingreso a los niveles sociales maduros.

El joven moderno psicológicamente se da en esta bipolaridad bio-social, buscando el equilibrio, de ahí la mayor inestabilidad, volubilidad y contradicción que crea las condiciones necesarias para expresarse en manifestaciones cada vez más colectivas; como agresividad desorganizada (violencia juvenil de los ainos 66 al 69 ), aislamiento y pacifidad por cl uso de drogas y marihuana, como contaminación de movimientos extranjeros (hipismo), y la expresión más nacional y reciente de incorporarse a grupos políticos de choque, tanto de derecha como de izquierda.

Hoy encontramos estas manifestaciones juveniles, mañana ¿Qué nos inquietatá de ellos? Creemos que ésta cuestión poco debería preocuparnos porque son expresión de contenidos que le son otorgados por el momento socio-cultural y variará con la cvolución histórica, pero el joven llámase o no adolescente, mantendrá sus características de ser en desarrollo, cuyos cambios básicos están determinados en gran medida por la herencia, modificada por su interrelación con el medio en que le toca nacer y vivir.

En otras palabras, el hombre en cualquiera ctapa de su estado evolutivo, se estructura no sólo por el aportc disposicional biológico (hereditario), sino tambión por la influencia del mundo de valores, pautas, normas y el sentido de su cxistencia que la cultura de su tiempo le entrega. De nodo quc un conocimiento de las caracteristicas de la sociedad, en cuanto a su organización sociopolítico-económica, nos entregará una visión más exacta de la concepción del hombre de esa cultura y una comprensión eabal del joven, pues éste tomat de la cultura los elementos que utiliza para su expresión. Se legará a caracterizar con certeza al joven sólo cuando se le ponga cn referencia al con- 
tex to socio-cultural del que proviene, porque siendo el hombre un ser social jo normal o patológico se origina o se reviste en la coexistencia polar in dividuo-medio social. Hay épocas de la cultura, medios sociales o situaciones ambientales humanas, que facilitan las expresiones anormales de la conducta.

\section{RESUMEN}

Los A.A. después de definir la pubertad como un fenómeno transicional biopsicológico establecen las diferencias entre nin̆o y adulto. Consideran la adolescencia como un fenómeno de maduración socio-cultural.

Con respecto a los adolescentes analizan las contradicciones internas y externas de esta etapa $y$ les peculiaridades de estas contradicciones, que permiten comportamientos criticos, para asi llegar a sus consideraciones sobre crisis puberal y crisis juvenil.

La exposicion de algunos de los resultados de la revisión de 266 historias clínicas de adolescenter, por ellos atendidos, la hacen con la intención de mostrar algunos hallazgos sobre factores causales de la patología enconirada, sus modos de expresarse, la dependencia a factores externos y su relación con problemáticas inherentes a este periodo de vida.

Concluyen que la patología está en gran medida condicionada por factores heredo-constitucionales aumque en importante porcentaje dependen de conflictiva familiar. Los modos de expresión están codeserminados por el momento socio-cultural histórico; los conflictos se somatizan con facilidad y las problemáticas se cosifican, en los adolescentes de hoy.

\section{SUMMARY}

The authors, after defining puberiy as a biopsychological transitional event, establish differences between the child and the adult. They consider adolescence as a socio cultural maturation phenomenom.

Reffering to adolescents, they analize the internal and external contradictions of this stage, its peculia- rities, that permit critical behaviors, and in this way, they arrive to their considerations about the puberal crisis and juyenile crisis.

They report some results of the revition of $266 \mathrm{cli-}$ nical cases of adolescents, with the intention of showing some findings about causal factors of pathology encountered, its ways of expression, dependency of external factors, and relation to preocupations inherents to this period of life.

They conclude that patbology is in great measure conditioned by heredo constitutional factors, although a great percentage depends of familiar conflictiveness.

The ways of expression are codetermined by the historical-socio-cultural moment; the conflicts are easily somutized, the preocupations are merchandized, in today's adolescents.

\section{BibLIOGRAFíA}

1.-Carmichael L. Manual de Psicología Infantil El Ateneo. Barcelona, 1969.

2.-Fischer E. Problemas de la Generación Joven. Ciencía Nueva, Madrid.

3.-Gunieri A., Torres, Rivas A., González G, de la Vega E. Estudio sobre Juventud Marginal Latinoamericana, Ed. Universitaria, S. A., Santiago Chile 1971.

4.- Jersil A. T. Psicología del Adolescente. Ed. Aguilar. Madrid, 1968.

5.- Marctse H. El Hombre Unidimensional. Ed. Seix Barrel, Barcelona, 1971.

6.-Mattelart A. y M. Juventud chilena - Rebeldía y Conformismo. Ed. Universitaria S. A. Santiago, Chile, 1970.

7.-Schonfeld W. A. La Psychiatrie del'adolescence: un défi pour tout les psychiatres. Confr. Psych. 7, 1971.

8.-Spranger S. Psicología de la edad juvenil. Selecta de Revista de Occidente, Madrid, 1965. 